\title{
Editorial: Magma-Rock and Magma-Mush Interactions as Fundamental Processes of Magmatic Differentiation
}

\author{
Anastassia Y. Borisova $^{1,2 *}$, Wendy A. Bohrson ${ }^{3}$ and Frank J. Spera ${ }^{4}$ \\ ${ }^{1}$ Géosciences Environnement Toulouse, GET/OMP (CNRS, UT3PS, CNES), Toulouse, France, ${ }^{2}$ Geological Department, \\ Lomonosov Moscow State University, Moscow, Russia, ${ }^{3}$ Department of Geology and Geological Engineering, Colorado School \\ of Mines, Golden, CO, United States, ${ }^{4}$ Department of Earth Science and Earth Research Institute, University of California, Santa \\ Barbara, CA, United States
}

Keywords: magma-rock interaction, magma-mush system, melt-rock interaction, melt-mush reaction, editorial

Editorial on the Research Topic

Magma-Rock and Magma-Mush Interactions as Fundamental Processes of Magmatic Differentiation

\section{OPEN ACCESS}

Edited and reviewed by:

Catherine Jeanne Annen,

University of Bristol, United Kingdom

*Correspondence:

Anastassia Y. Borisova anastassia.borisova@get.omp.eu

Specialty section: This article was submitted to Petrology,

a section of the journal

Frontiers in Earth Science

Received: 08 February 2021 Accepted: 11 February 2021 Published: 25 March 2021

Citation: Borisova AY, Bohrson WA and Spera FJ (2021) Editorial: MagmaRock and Magma-Mush Interactions

as Fundamental Processes of

Magmatic Differentiation.

Front. Earth Sci. 9:665588.

doi: 10.3389/feart.2021.665588
Virtually all terrestrial magmas, in all geodynamic settings, interact, sometimes profoundly, with surrounding rocks during their generation, residence at depth, and ascent through the asthenosphere and lithosphere. This results in inevitable interactions (exchanges of heat and matter) described as magma/melt-rock or magma/melt-mush interactions.

The major processes that happen when silicate magma is in contact with surrounding rocks were first defined in the pioneering studies of Bowen (1928) who identified two types of reactions: partial melting of the wall rocks and mineral dissolution in silicate melt. These reactions, which are ubiquitous during magma evolution, are commonly referred to as 'assimilation' (DePaolo, 1981), but may more broadly be called open-system processes. Assimilation, magma mixing, degassing, magma-rock and fluid-rock interactions control magma and fluid composition, metal and volatile contents, and magma physical-chemical properties and mobility. Consequently, the interactions influence volcanic activity, ore deposit formation, growth of the crust, and terrestrial climate. However, the degree, rates, and mechanisms of these reactions are poorly quantified owing to a lack of natural and experimental data and predictive models.

This research volume 'Magma-Rock and Magma-Mush Interactions as Fundamental Processes of Magmatic Differentiation' is devoted to documenting recent achievements in the fields of kinetics and thermodynamics as well as the petrologic and geochemical consequences of magma-rock, meltrock, and melt-mush interactions. New observations of natural systems and laboratory experimental approaches that address how magma, melt, mush and rock interact are represented by seven articles (Baudouin and Parat; Borisova et al.; Boulanger et al.; Pistone et al.; Sanfilippo et al.; Tassara et al.; Borisova et al.). Examples of these types of interactions include mantle metasomatism (Baudouin and Parat), mineral-melt reaction in the planetary ultramafic protocrust (Borisova et al.) and in the terrestrial mantle (Borisova et al.; Sanfilippo et al.), melt-mush interaction in the crust (Pistone et al.), and thermal and chemical modification of preexisting mushy magma by intrusion of high specific enthalpy (enthalpy per unit mass) magma (Boulanger et al.). The melt-rock interactions also affect the redox state of percolating melts that may become enriched in ore-forming metals (Tassara et al.). 


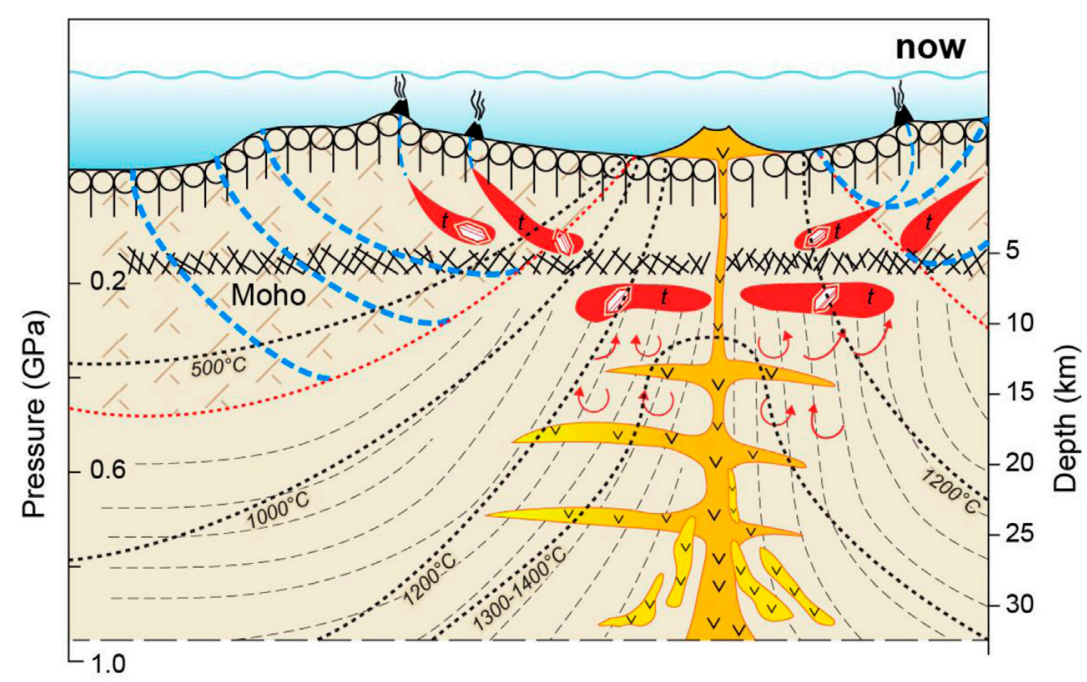

Liquid water ocean $\ldots \ldots$ Deserpentinization front

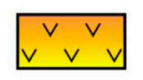

Mantle-derived basaltic magma

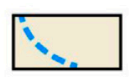

Oceanic water-derived

hydrothermal fluids

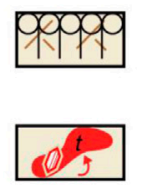
Mafic-ultramafic
lithosphere

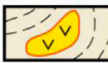

Mantle-derived (basaltic)

magma intrusion and sills in harzburgite

Felsic melts and aqueous fluids

$x \times x \times x \times y$ Moho transition zone

FIGURE 1 | Model of formation of the modern chromitite-dunite zone in the oceanic lithosphere after Borisova et al. Intrusion of mantle-derived magmas into hydrated (serpentinized) mantle initiated the dehydration process and prograde metamorphism. The dehydrated peridotite-basaltic melt interaction produces dunitechromitite rock sequence associated to the felsic melts and aqueous fluids in the mantle and the mantle-crust transition zone. Borisova et al. demonstrate that similar mechanism of the hydrated peridotite-basaltic melt interaction and partial melting of the peridotite might happen and result in felsic crust formation on early steps of the protocrust evolution during Hadean and Noachian eons on Earth and Mars, respectively.

This spectrum of processes plays a major role in the composition, thickness, and age of the mantle lithosphere and the associated crust.

\section{Experimental Studies of Melt-Rock and Melt-Mush Interactions}

The experimental data represented by Borisova et al. suggest that the interaction of serpentinized peridotites (serpentinites) with basaltic liquids can lead to the formation of felsic liquids which may be the prototype of the first continental crust existing on Earth and Mars just after the solidification of their protocrusts and its interaction with seawater (Hadean and Noachian, respectively). The authors demonstrate that this interaction of serpentinized peridotites with basaltic liquids is responsible for the production of felsic crust at depths less than $10 \mathrm{~km}$ in geodynamic situations independent of oceanic plate subduction (Figure 1). This scenario provides a mechanism for crust generation in accordance with the existing models of pre plate tectonic processes on Earth and Mars.

Borisova et al. have experimentally established the physicalchemical conditions which produce bulk assimilation of serpentinized rocks by basaltic liquids, the formation of magmas generated by melting of serpentinites, and processes which occur along the petrologic Moho between the mantle and the oceanic crust. The generation of depleted MORB melts, high-Mg-Cr cumulates, chromitites, and oceanic boninites and andesites is reliably explained by the efficient reaction of initially anhydrous basaltic melts with serpentinized lithospheric mantle. The work by Borisova et al. challenges the routine interpretation of variations in chemical and isotopic composition of oceanic lavas (e.g., MORB and OIB) solely in terms of deep mantle plume source heterogeneities or/and mechanism of partial melting. Possible shallow-level interactions should not be neglected.

Pistone et al. provided new experimental data applicable to felsic melt and gas mobilization during magma solidification. 
These processes may play a major role in magma fractionation at shallow depths $(<10 \mathrm{~km})$, where magmas stall rheologically and solidify. These experiments suggest that melt and gas extraction from cooling mushes increases in proximity to their solidus and can operate efficiently through gas filter pressing during cooling. Pistone et al. made estimates of the mechanisms and rates of segregation of gas-rich, crystal-poor magmas to form felsic dykes or eruptible systems feeding volcanoes.

\section{Study of Natural Systems: Subcontinental Lithosphere Mantle (SCLM) Setting}

Different physical and chemical parameters (e.g., pressure, oxygen fugacity, composition of magma, rock, or mush) provide fundamental controls on the dynamics and nature of magma-rock-mush interaction. For example, the final rock composition may be influenced, in part, by the degree of equilibrium reached between magma/melt and crystalline phases, and evidence of equilibrium-disequilibrium relationships will likely be preserved in the compositions of minerals rather than in the textures. Energy and mass transfer are also critical controls; for example, rock partial melting and associated contamination of magma are directly related to enthalpy produced during fractional crystallization of a magmatic system and the ability of anatectic melt to be transported into resident magma.

The study by Tassara et al. represents how the process of the melt-peridotite interaction controls the magma oxidation state and therefore the magma metallogenic fertility (Southern Patagonia). These authors demonstrate how changes in the redox state of magmas ascending through the SCLM can favor efficient extraction of $\mathrm{Au}$ and related metals from mantle sulfide minerals and melts. This study demonstrates that such interactions would exert a control on the localization of crustal provinces endowed with gold deposits. Thus, knowledge of the redox conditions prevailing in the SCLM as well as the mechanisms of the percolating melt-rock interactions are important for predicting the location and richness of metallogenic provinces (Au etc.).

Baudouin and Parat propose a physical-chemical model of the origin of phlogopite-olivine nephelenites erupted during the early stage rifting (North Tanzanian Divergence). Metasomatism via percolation of deep asthenospheric $\mathrm{CO}_{2}$-rich alkaline magmas during their ascent produces a range of mantle rock compositions in the thick SCLM. The authors demonstrate that percolation of deep asthenospheric $\mathrm{CO}_{2}$-rich alkaline magmas might explain phlogopite crystallization and production of such enigmatic lithologies such as glimmerite (consisting almost entirely of phlogopite). The process also affects the rheology of the Tanzanian lithosphere.

\section{Study of Natural Systems: Mid-Oceanic Ridge Setting}

Sanfilippo et al. present a natural example of melt channelization and the related melt-rock interaction by reactive porous flow (RPF) of basaltic melt through primitive mafic (olivine gabbro) crystal mush. This example is reported in apparently homogeneous olivine gabbro within a section of the plutonic footwall of the Atlantis Bank core complex on the Southwest Indian Ridge (International ocean discovery program hole U1473A). The cryptic changes toward more evolved compositions are impossible to detect on textural evidence alone. The authors detail that neither crystallization of trapped melt nor diffusion can account for the observed trace element signatures of the minerals. Major- and trace element mineral signatures reveal the occurrence of zoning profiles produced by a process of dissolution-precipitation under decreasing temperature conditions. The melt-rock reaction and reactive porous flow similar to that reported by Sanfillipo et al. may potentially be responsible for a significant proportion of crystal and melt modification in magma reservoirs.

Boulanger et al. reported magma reservoir formation and evolution at a slow-spreading center based on an example of ODP Hole 735B (Atlantis Bank, Southwest Indian Ridge). The authors performed in situ micro-analyses of the cumulative phases that document magma emplacement processes and provide evidence for ubiquitous reactive porous flow during differentiation. Boulanger et al. show that the whole section, and related geochemical unit, constitute a single magmatic reservoir, in which the lower unit is formed by stacked primitive sills formed by repeated recharge of primitive melts and melt-present deformation. The melt-rock interactions led to partial assimilation of the crystallizing primitive cumulates, and hybridization with their interstitial melts. The transport of the hybrid melts progressively collected in the overlying mushy part of the reservoir (upper unit) was governed by upward reactive porous flow, and progressive differentiation and accumulation of evolved melts at the top of the reservoir. Boulanger et al. attempted to address timescales for the formation of the reservoir by comparison with preexisting data and models for magma reservoir at slow-spreading ridges. These results provide the first integrated model for magma reservoir formation in the slow-spreading oceanic crust. The model illuminates new perspectives for the comprehension of mush-dominated igneous reservoirs dynamics in the oceanic lithosphere.

\section{AUTHOR CONTRIBUTIONS}

All authors listed have made a substantial, direct, and intellectual contribution to the work and approved it for publication. 


\section{REFERENCES}

Bowen, N. L. (1928). The evolution of the igneous rocks. Princeton, NJ: Princeton University Press.

DePaolo, D. J. (1981). Trace element and isotopic effects of combined wallrock assimilation and fractional crystallization. Earth Planet. Sci. Lett. 53, 189-202. doi:10.1016/0012-821x(81) 90153-9
Conflict of Interest: The authors declare that the research was conducted in the absence of any commercial or financial relationships that could be construed as a potential conflict of interest.

Copyright (C) 2021 Borisova, Bohrson and Spera. This is an open-access article distributed under the terms of the Creative Commons Attribution License (CC BY).

The use, distribution or reproduction in other forums is permitted, provided the original author(s) and the copyright owner(s) are credited and that the original publication in this journal is cited, in accordance with accepted academic practice. No use, distribution or reproduction is permitted which does not comply with these terms. 